\title{
Helicobacter pylori
}

\author{
B Drumm
}

Spiral organisms have been noted on the gastric mucosa on many occasions over the last 100 years. In 1975, Steer and Colin-Jones associated the presence of Gram negative bacteria on the gastric mucosa with gastritis. ${ }^{1}$ However, their failure to culture the organism resulted in the finding being ignored. It was not until Warren and Marshall's report, in 1983, describing an association between the presence of spiral organisms on the gastric mucosa and antral gastritis in adults, that interest in a pathogenic role for bacteria in gastritis was rekindled. ${ }^{2}$ Subsequent studies in adults and children have confirmed this association as well as a strong association with duodenal ulcer disease. ${ }^{34}$

This bacterium was initially referred to as a campylobacter like organism because of its morphologic resemblance to Campylobacter jejuni. After its successful culture, in 1984, the name 'Campylobacter pyloridis' was applied to the organism but this was later changed, for grammatical reasons, to Campylobacter pylori. It has recently been designated as the type species of a new genus-termed 'Helicobacter'. The organism, now called Helicobacter pylori, has been the dominant issue in recent studies on peptic ulcer disease.

$H$ pylori is present on the gastric mucosa beneath the gastric mucus layer and within it. ${ }^{36}$ The bacterium does not invade the epithelium. It is usually found on the antral mucosa but may also be present in other parts of the stomach. The organism colonises gastric tissue only. ${ }^{78} \mathrm{H}$ pylori may be isolated from other sites such as the duodenum, oesophagus, and rectum but only if there is gastric metaplasia at these sites. ${ }^{8}$

Antral biopsy specimens from colonised individuals show an increase in the number of mononuclear cells and in most cases there is an increased number of neutrophils present. ${ }^{7}$ There is also depletion of intracellular mucin. Ultrastructural studies have demonstrated $H$ pylori adhering to the surface of the gastric epithelium. ${ }^{3}$ This adherence is associated with pedestal formation, a feature identical to that seen with enteropathogenic Escherichia coli attaching to intestinal cells.

Paediatrics, University College

Dublin

Correspondence to: Professor B Drumm, Our Lady's Hospital for Sick Children, Crumlin, Dublin 12,

Republic of Ireland.
$H$ pylori is a spiral or curved, Gram negative, motile organism which has multiple unipolar flagellae. It produces large amounts of urease and is also catalase and oxidase positive. ${ }^{3} 5$
$H$ pylori can be successfully cultured under conditions of reduced oxygen but does not grow under aerobic or anaerobic conditions. ${ }^{5}$ Growth is optimal at $37^{\circ} \mathrm{C}$. It has a long incubation period of five to seven days when grown in primary culture. $H$ pylori can be grown on solid media such as charcoal, blood, or Skirrow's medium. A haemin source is always necessary for growth. Growth in liquid broth is possible when brucella broth is supplemented with fetal bovine serum. 5

The bacterium is sensitive in vitro to penicillin, ampicillin, amoxycillin, erythromycin, gentamicin, kanamycin, rifampicin, metronidazole, tetracycline, and cephalothin. It is also sensitive to bismuth salts. Resistance to vancomycin, sulphonamides, trimethoprim, and nalidixic acid has been documented. ${ }^{5}$

To date no serotyping system has been developed. It appears possible to distinguish between strains using restriction endonuclease enzyme DNA digest pattern. ${ }^{9}$ Using this method, isolates from each individual are almost always different, although the same strain can be isolated sequentially from an individual.

\section{$H$ pylori and gastritis}

After Warren and Marshall's observation there have been many reports confirming an association between the presence of these organisms and gastritis in adults. ${ }^{34}$ Almost all individuals with chronic antral gastritis are colonised. It was postulated that the organism could be colonising gastric tissue as a result of inflammation rather than as a cause of it. Subsequent studies in children demonstrated not only an association of $H$ pylori with gastritis, however, but that the organism is associated specifically with primary or unexplained gastritis. ${ }^{10}$

Further evidence implicating $H$ pylori as a gastric pathogen has come from volunteer studies. Two volunteers have ingested the organism and both developed gastritis after gastric colonisation. ${ }^{11} 12$

$H$ pylori appears to have been associated with 'epidemic gastritis'. In 1979, Ramsey et al reported 17 healthy volunteers and one patient with Zollinger-Ellison syndrome who became profoundly hypochlorhydric while undergoing studies of acid secretion. These subjects simultaneously developed gastritis, ${ }^{13}$ and it was subsequently possible to demonstrate rising titres 
of $H$ pylori specific antibody after the onset of gastritis. ${ }^{14}$ It should be noted that Morris became transiently achlorhydric when he ingested $H$ pylori. ${ }^{12}$ The reasons for this apparent achlorhydria at the time of acute infection with $H$ pylori are not understood.

Newell et al have described the presence of $H$ pylori in primates and found a similar association with gastritis in these animals. ${ }^{15}$ A closely related organism, Helicobacter mustelae, has been identified on the gastric mucosa of ferrets. ${ }^{5}$ This organism is also associated with gastritis. Ferrets are frequently found to have gastritis and peptic ulcer disease. Gnotobiotic piglets can be experimentally infected with $H$ pylori. These piglets develop gastritis in association with gastric colonisation by $H$ pylori. ${ }^{16}$

Perhaps the strongest evidence supporting a pathogenic role for $H$ pylori in gastritis comes from treatment studies. These have demonstrated that eradication of $H$ pylori from the stomach is associated with resolution of antral gastritis. ${ }^{17-20}$

\section{$H$ pylori and peptic ulceration \\ DUODENAL ULCER DISEASE}

Duodenal ulcer disease is associated with chronic antral gastritis. ${ }^{21}$ It is not surprising therefore that a strong association has now been demonstrated between the presence of $H$ pylori on the gastric antrum and chronic duodenal ulcer disease. ${ }^{3} 4$ The organism is present on the gastric mucosa in approximately $80 \%$ of adults with duodenal ulcers. ${ }^{4} H$ pylori does not colonise the duodenal mucosa except at sites of gastric metaplasia. ${ }^{78}$ This trophism for gastric tissue makes $H$ pylori an unlikely candidate to cause directly duodenal ulceration. It has been proposed that gastric metaplasia in the duodenum serves as a precursor of duodenal ulceration by providing a nidus for $H$ pylori colonisation and subsequent inflammation. ${ }^{8}$

Although the role of $H$ pylori in duodenal ulceration is not understood, its importance in this condition is demonstrated by the effect of clearing this organism on duodenal ulcer disease. Relapse rates for duodenal ulcer disease are appreciably reduced when $H$ pylori is cleared from the gastric mucosa. ${ }^{17}$

\section{GASTRIC ULCER DISEASE}

The association of $H$ pylori and antral gastritis with gastric ulcer disease is less noticeable. The organism is found in approximately $60 \%$ of adults with gastric ulceration. ${ }^{4}$ This may be due to the fact that a significant number of gastric ulcers are secondary, being related to drug and other ingestions.

\section{$H$ pylori in children}

Several studies have confirmed an association between gastric colonisation with $H$ pylori and antral gastritis in children. ${ }^{6} 10$ 22-26 There also appears to be a strong association between $H$ pylori associated antral gastritis and chronic duodenal ulcer disease in children. ${ }^{622} 26$

In 1987, a prospective study in Toronto, examined antral biopsy specimens from 67 of 71 children who underwent upper gastrointestinal endoscopy. ${ }^{6}$ Forty nine of these children had normal antral histology and 18 had histological gastritis. Of these 18, 10 had unexplained gastric inflammation whereas eight had an underlying cause identified (gastroduodenal Crohn's disease, eosinophilic gastroenteritis, drug ingestion). Seven of the 10 children with primary or unexplained gastritis had $H$ pylori isolated from the gastric mucosa. In contrast none of the children with secondary gastritis had $H$ pylori isolated. Also none of the 49 children with normal histology had the bacterium cultured from biopsies. A retrospective study using gastric biopsy specimens, obtained over a three year period, resulted in identical findings. ${ }^{10}$ These studies provided strong evidence implicating $H$ pylori as a gastric pathogen.

The number of children colonised with $H$ pylori is very low, in Western societies, in comparison with the number of adults colonised. ${ }^{22} 27$ Colonisation increases progressively with age. ${ }^{27}$ The prospective study in Toronto found $H$ pylori gastritis in only $10 \%$ of children undergoing endoscopy for upper gastrointestinal symptoms. ${ }^{6}$ Hill et al found the organism in six of $38(16 \%)$ children studied in Australia. ${ }^{23}$ Cadranel et al found $H$ pylori in eight of 25 children (32\%) studied in Belgium. ${ }^{24}$ More recently Glassman et al detected the organism in $10 \%$ of children undergoing upper endoscopy in New York. ${ }^{25}$ Studies of children, in Western societies, indicate that colonisation almost never occurs below 8 years of age. ${ }^{610222325}$

\section{PEPTIC ULCER DISEASE}

In two prospective studies from Toronto $H$ pylori was found in association with duodenal ulcer disease in all 13 cases in which ulcers were detected. ${ }^{62}$ In a retrospective study Kilbridge et al found $H$ pylori to be present on the antral mucosa in eight of nine patients who had duodenal ulcer disease. ${ }^{26}$ Therefore, although duodenal ulcer disease is uncommon in children, there is a strong correlation between the presence of such ulceration and $H$ pylori associated antral gastritis. An association with gastric ulcer disease has not been clearly demonstrated as primary gastric ulceration is rare in children. ${ }^{28}$

\section{SYMPTOMS}

There has been no major prospective study of presenting symptoms in children colonised with $H$ pylori. Epigastric pain and vomiting appear to be major presenting symptoms. ${ }^{62425}$ Children with duodenal ulcer disease have more noticeable symptoms than those with gastritis alone. ${ }^{19}$

Clearing of $H$ pylori from the gastric mucosa and resultant improvement or healing of gastritis is associated with a definite improvement in symptoms. This improvement in symptoms is, however, primarily seen in those patients who have associated duodenal ulcer disease. ${ }^{19}$ Oderda et al found that clearing $H$ pylori from the gastric mucosa using amoxycillin alone resulted in the disappearance of symptoms in children. ${ }^{29}$ Although the infection recurred in 
most of the children, however, very few developed a relapse of symptoms. Therefore, $H$ pylori associated gastritis, in the absence of ulcer disease, may not be a significant cause of symptoms. This supposition is supported by the finding that $H$ pylori colonisation is widespread in the adult community as well as in siblings of children with documented $H$ pylori gastritis. ${ }^{22} 27$ Large prospective studies of children undergoing endoscopy will be needed to clarify this issue.

\section{ENDOSCOPIC FINDINGS}

Children and adults with $H$ pylori associated gastritis often have normal endoscopic findings. ${ }^{6} 18$ It is essential to obtain antral biopsy specimens during endoscopy. These specimens may demonstrate appreciable gastritis microscopically in the absence of endoscopic findings.

\section{Diagnosis of $\boldsymbol{H}$ pylori infection \\ CULTURE}

The 'gold standard' for diagnosis of $H$ pylori infection is culture of the organism from an antral biopsy specimen. The specimen can be ground and the material used to inoculate blood agar, chocolate agar, or Skirrow's medium. ${ }^{56}$ These inoculations should be done within 60 minutes of the biopsy being taken. The plates are incubated at $37^{\circ} \mathrm{C}$ under microaerophilic conditions for up to seven days. $H$ pylori colonies are very small and translucent and usually very few colonies are present on a primary culture from a child. The organism is identified as $H$ pylori if it is positive for urease, catalase, and oxidase and produces a negative reaction for hippurate hydrolysis and nitrate reduction. ${ }^{5}$

\section{STAINING TECHNIQUES}

Because of its spiral appearance and unique location within and beneath the gastric mucus layer, $H$ pylori can be demonstrated by various stains on histological sections. The WarthinStarry silver stain has been widely used to demonstrate the organism. The silver stain allows for easy identification of darkly staining bacteria against a bright background. This method of identifying $H$ pylori correlates very well with culture in children. ${ }^{62}$ However, these stains are tedious to perform. Simpler methods include the use of a giemsa stain which is also very effective. ${ }^{729}$

\section{UREASE TESTS}

A positive urease reaction occurring when a gastric biopsy specimen is incubated in a urea medium is usually indicative of the presence of $H$ pylori on the gastric mucosa. The biopsy specimen is placed on a Christensen's urea slope and a positive reaction is indicated by a change in colour of the medium from tan to pink. ${ }^{30}$ Commercial tests for urease production can identify $H$ pylori in approximately $90 \%$ of biopsies from colonised children. ${ }^{29}$

Urease breath tests have been developed to detect $H$ pylori colonisation by non-invasive means. Labelled urea $\left({ }^{13} \mathrm{C}\right.$ or $\left.{ }^{14} \mathrm{C}\right)$ is ingested by individuals and the breakdown of urea by bacterial urease results in the appearance of labelled carbon dioxide in the expired air of colonised subjects. ${ }^{31}{ }^{32}$ Quantitation of expired labelled carbon dioxide allows for the indirect diagnosis of $H$ pylori gastritis. These tests are extremely sensitive. $\mathrm{A}^{13} \mathrm{C}$ label is more ideal for use in children as it is not radioactive. The label, however, is very expensive and the test requires the use of mass spectrometry.

\section{SEROLOGY}

A $H$ pylori specific IgG serologic response is both highly sensitive (96\%) and highly specific (99\%) in identifying children with $\mathrm{H}$ pylori associated gastritis. ${ }^{22}$ Enzyme linked immunoabsorbent assay systems are now widely used to detect this serological response using various $H$ pylori antigenic preparations. The IgG immune response is the most sensitive indicator of infection. The IgA immune response is also used whereas specific IgM measurements are not reliable. ${ }^{27}$ Serological testing may therefore, present a very good diagnostic test for $H$ pylori associated gastritis in children.

\section{Epidemiology}

Serology has provided the optimal means of studying the incidence of $H$ pylori colonisation. In Western countries, studies have shown that children and young adults are rarely colonised by $H$ pylori. ${ }^{22}$ The incidence of infection increases progressively with age until approximately $50-60 \%$ of the population are colonised at 60 years. $^{27}$ The reason for this increase in colonisation with age is not known. There are indications that colonisation occurs earlier in life and ultimately effects almost the entire population in less developed countries. ${ }^{33}$

$H$ pylori has not been isolated from a site outside of the gastrointestinal tract. There is a single report of successful culture of the organism from dental plaque. ${ }^{34}$ There is no known natural reservoir in the environment for this bacterium. A recent study of children and their families provides strong evidence supporting person to person transmission of this organism. ${ }^{22}$ In this study, $73 \%$ of parents of $H$ pylori positive children had a $H$ pylori specific serological response, whereas only $24 \%$ of parents of children who were not colonised had such a response. The strongest evidence of person to person spread was provided by studies on the siblings of the $H$ pylori colonised children. Eighty one percent of these siblings were found to have serological evidence of $H$ pylori colonisation in comparison with $13 \%$ of controls.

It is unclear whether members of a family are colonised by the same strain of $H$ pylori. Strain identification using DNA digest patterns has shown the same strain infecting several members of the same family in Europe. In Canada, however, young siblings were shown to be colonised by different strains. ${ }^{9}$ Furthermore, it appears that an individual can harbour more than one strain of the organism simultan- 
eously. ${ }^{35}$ Further studies are therefore needed to clarify this issue.

\section{Treatment}

Eradication of $H$ pylori from the gastric mucosa is correlated with healing of antral gastritis in adults and children. ${ }^{17-20} 36$ This occurs irrespective of the particular agent that is used to clear the organism. While $H$ pylori is sensitive to many antibiotics in vitro, this sensitivity is not correlated with clearing of the organism in vivo. ${ }^{37}$ It has been postulated that the failure of antibiotic monotherapy adequately to clear $H$ pylori in vivo may be due to the lack of efficacy of the antibiotics in the acid environment of the stomach. ${ }^{37}$

$H$ pylori is optimally cleared from the gastric mucosa using combinations of bismuth salts and various antibiotics. ${ }^{20} 37$ Treatment with bismuth salts alone is successful in clearing $H$ pylori from the gastric mucosa in approximately $50 \%$ of adult patients. ${ }^{17} 1820$ Recurrence of infection is common after treatment of $H$ pylori by bismuth alone or antibiotic monotherapy. ${ }^{20} 29$

Oderda et al treated children with amoxycillin. Immediately after treatment the organism was absent from gastric biopsy specimens in $85 \%$ of treated children. ${ }^{29}$ However, three months later the infection was present in $73 \%$ of these children. Combination therapy using a bismuth preparation and an antibiotic such as ampicillin or metronidazole increases the percentage of adult patients in whom the organism is cleared. ${ }^{20}{ }^{37}$ Studies from Leeds and Toronto have reported clearing of $H$ pylori from the antral mucosa in $70 \%$ of children treated with bismuth subsalicylate or tripotassium dicitrato bismuthate and oral ampicillin (MJ Mahony, JI Wyatt, JM Littlewood; British Society of Gastroenterology, Autumn 1989). ${ }^{19}$ In Italy, 94\% of children treated with amoxycillin and tinidazole were successfully cleared of $H$ pylori and six months later $75 \%$ of them remained clear. ${ }^{36}$ There are, however, ethical considerations in performing repeat endoscopies on asymptomatic children and long term relapse rates will be difficult to determine. More recently triple therapy using bismuth combined with two antibiotics, such as amoxycillin and metronidazole, has been reported to be successful in long term eradication of $H$ pylori. Evidence is accumulating that $H$ pylori rapidly develops resistance to antibiotics such as metronidazole, however, although resistance is less likely to occur when the antibiotic treatment is combined with bismuth. Such triple therapy is not presently justified in situations other than controlled trials.

\section{DUODENAL ULCER DISEASE}

$\mathrm{H}_{2}$ antagonists have appreciably reduced the morbidity associated with chronic peptic ulcer disease. However, relapse of ulcer disease occurs in most patients (children and adults) after treatment is stopped. ${ }^{17} 28$ These agents have no effect on $H$ pylori colonisation or on the chronic gastritis that is invariably associated with duodenal ulcer disease. ${ }^{1820}$ Bismuth salts are as successful as $\mathrm{H}_{2}$ antagonists in healing duodenal ulcers. More importantly, duodenal ulcer disease relapses less frequently after treated with bismuth. ${ }^{38}$ This appears to be due to the effect of bismuth on $H$ pylori associated antral gastritis. ${ }^{17}$ Recent studies have shown a considerable reduction in the rate of relapse of duodenal ulcer disease if $H$ pylori is cleared from the gastric mucosa during treatment. ${ }^{17}$ Recurrence of ulcer disease in such patients is associated with reinfection with $H$ pylori.

\section{RECOMMENDATION ON TREATMENT}

While the search is continuing for the optimal treatment of $H$ pylori associated gastritis, we have to define who requires treatment. There is, at present, no evidence to indicate that treatment is necessary for $H$ pylori associated gastritis in the abscence of ulcer disease. Chronic duodenal ulcer disease in children has a natural history identical to duodenal ulcer disease in adults. ${ }^{28}$ The evidence from studies in adults would seem to justify treating children with duodenal ulcer disease using colloidal bismuth subcitrate (bismuth chelate, tripotassium dicitrato bismuthate) for four weeks combined with an antibiotic such as ampicillin or metronidazole for two weeks. Mahony et al used colloidal bismuth subcitrate, $240 \mathrm{mg}$ twice a day in children and did not encounter bismuth toxicity (MJ Mahony, JI Wyatt, JM Littlewood; British Society of Gastroenterology, Autumn 1989).

\section{Conclusion}

$H$ pylori is a cause of chronic antral gastritis. Furthermore, clearing of $H$ pylori from the gastric mucosa reduces the rate of relapse of duodenal ulcer disease. Several questions still need to be studied if we are to fully understand the role of this bacterium in peptic disease. There have been hypotheses published to explain how $H$ pylori colonisation could result in chronic duodenal ulcer disease. These hypotheses have relied on the ability of $H$ pylori to break down mucus. A recent study indicates that $H$ pylori is not effective in degrading mucus. ${ }^{39}$ This association between antral gastritis, $H$ pylori, and duodenal ulceration is therefore still not understood. Why does the organism colonise gastric tissue only? How does $H$ pylori cause inflammation? Is there a natural reservoir for this organism in the environment? Research projects are presently being undertaken in several centres that will hopefully provide answers to these questions.

I wish to acknowledge Dr Liam Carroll for providing a critical review of this manuscript and Sharon Bennis for typing and proof reading.

1 Steer HW, Colin-Jones DG. Mucosal changes in gastric ulcertion and their response to carbenoxolone sodium. Gut 1975; tion and their.

2 Warren JR, Marshall BJ. Unidentified curved bacilli on gastric epithelium in active chronic gastritis. Lancet 1983; :1273-5

3 Goodwin CS, Armstrong JA, Marshall BJ. Campylobacter pyloridis, gastritis, and peptic ulceration. F Clin Pathol 1986;39:353-65.

4 Blaser MJ. Gastric campylobacter-like organisms, gastritis, and peptic ulcer disease. Gastroenterology 1987;93:371-83. 5 Goodwin CS, Armstrong JA, Chilvers T, et al. Transfer of 
Campylobacter pylori and Campylobacter mustelae to Helicobacter gen nov as Helicobacter pylori comb nov and Helicobacter mustelae com nov, respectively. International foumal of Systematic Bacteriology 1989;39:397-405.

6 Drumm B, Sherman P, Cutz E, Karmali M. Association of Campylobacter pylori on the gastric mucosa with antral Campylobacter pylori on the gastric mucosa with antral

7 Wyatt JI, Dixon MF. Chronic gastritis-a pathogenic approach $f$ Pathol 1988;154:113-24.

8 Wyatt JI, Rathbone BJ, Dixon MF, Heatley RV. Campylobacter pyloridis and acid induced gastric metaplasia in the pathogenesis of duodenitis. F Clin Pathol 1987;40:841-8.

9 Simor AE, Shames B, Drumm B, Sherman P, Low DE Penner JL. Typing of Campylobacter pylori by bacterial DNA restriction endonuclease analysis and determination of plasmid profile. $\mathcal{F}$ Clin Microbiol 1990;28:83-6.

10 Drumm B, O'Brien A, Cutz E, Sherman P. Campylobacter pyloridis associated primary gastritis in children. Pediatrics 1987;80:192-5.

11 Marshall BJ, Armstrong JA, McGechie DB, Glancy RJ. Attempt to fulfil Koch's postulates for pyloric campylobacter. Med ₹ Aust 1985;142:436-9.

12 Morris A, Nicholson G. Ingestion of Campylobacter pyloridis causes gastritis and raised fasting gastric pH. Am f Gastrocenterol $1987 ; 82: 192-9$.

13 Ramsey EJ, Carey KV, Peterson WL, et al. Epidemic gastritis with hypochlorhydria. Gastroenterology 1979;76: $1449-57$.

14 Peterson W, Lee E, Skoglund M. The role of Campylobacter pyloridis in epidemic gastritis with hypochlorhydria.

15 Newell DG, Hudson MJ, Baskerville A. Isolation of a gastric campylobacter-like organism from the stomach of four Rhesus monkeys, and identification as Campylobacter pylori. F Med Microbiol 1988;27:41-4.

16 Krakowka S, Morgan DR, Kraft WG, Leunk RD. Establishment of gastric Campylobacter pylori infection in the neonat of

17 Coghlan JG, Gilligan D, Humphries $\mathrm{H}$, et al Campylobacter pylori and recurrence of duodenal ulcers - a 12 month pylori and recurrence of duodenal ulcer

18 Humphreys H, Bourke S, Dooley C, et al. Effect of treatment on Campylobacter pylori in peptic disease: a randomised prospective trial. Gut 1988;29:279-83.

19 Drumm B, Sherman P, Chiasson D, Karmali M, Cutz E Treatment of Campylobacter pylori-associated antral gastriTreatment of Campylobacter pylori-associated antral gastri-
tis in children with bismuth subsalicylate and ampicillin. tis in children with bismuth

20 Rauws EAJ, Langenberg W, Houthoff HJ, Zanen HC, Tytgat GNJ. Campylobacter pyloridis-associated chronic active antral gastritis. Gastroenterology 1988;94:33-40.

21 Schrager J, Spink R, Mitra S. The antrum in patients with duodenal and gastric ulcers. Gut 1967;8:497-508.

22 Drumm B, Perez-Perez GI, Blaser MJ, Sherman PM. Intrafamilial clustering of Helicobacter pylori infection. $N E n g l$ f Med 1990;322:359-63.

See related paper on $\mathrm{p} 1212$.
23 Hill R, Pearman J, Worthy P, Caruso V, Goodwin S, Blincow E. Campylobacter pyloridis and gastritis in children. Lancet 1986;i:387.

24 Cadranel S, Goossens H, De Boeck M, Malengreau A Rodesch P, Butzler JP, Campylobacter pyloridis in childRodesch P, Butzler JP, Car

25 Glassman MS, Schwarz SM, Medow MS, et al. Campylobacter pylori-related gastrointestinal disease in children Dig Dis Sci 1989;34:1501-4.

26 Kilbridge PM, Dahms BB, Czinn SJ. Campylobacter pyloriassociated gastritis and peptic ulcer disease in children. $A m$ f Dis Child 1988;142:1149-52.

27 Perez-Perez GI, Dworkin BM, Chodos JE, Blaser MJ. Campylobacter pylori antibodies in humans. Ann Intern Med 1988;109:11-7.

28 Drumm B, Rhoads JM, Stringer DA, Sherman PM, Ellis LE, Durie PR. Peptic ulcer disease in children: etiology, clinical findings, and clinical course. Pediatrics 1988;82:410-4.

29 Oderda G, Dell'olio D, Morra I, Ansaldi N. Campylobacter pylori gastritis: long term results of treatment with amoxycillin. Arch Dis Child 1989;64:326-9.

30 McNulty CAM, Dent JC, Uff JS, Gear MWL, Wilkinson SP. Detection of Campylobacter pylori by the biopsy urease test: an assessment in 1445 patients. Gut 1989;30:1058-62.

31 Graham DY, Evans DJ Jr, Alpert LC, et al. Campylobacter pylori detected noninvasively by the ${ }^{13} \mathrm{C}$-urea breath test. pylori detected noninvasi

32 Bell GD, Weil J, Harrison G, et al. ${ }^{14} \mathrm{C}$-urea breath analysis, a non-invasive test for Campylobacter pylori in the stomach. Lancet 1987; i:1367-8.

33 Megraud F, Brassens-Rabbe MP, Denis F, Belbouri A, Hoa DQ. Seroepidemiology of Campylobacter pylori infection in various populations. $\mathcal{F}$ Clin Microbiol 1989;27: 1870-3.

34 Shames B, Krajden S, Fuksa M, Babida C, Penner JL. Evidence for the occurrence of the same strain of Campylobacter pylori in the stomach and dental plaque. 7 Clin Microbiol 1989;27:2849-50.

35 Beji A, Vincent P, Darchis I, Husson MO, Cortot A, Leclerc $H$. Evidence of gastritis with several Helicobacter pylori strains. Lancet 1989;ii:1402-3.

36 Oderda G, Holton J, Altare F, Vaira D, Ainley C, Ansaldi N. Amoxycillin plus tinidazole for Campylobacter pylori gastritis in children: assessment by serum IgG antibody, gastritis in children: assessment by serum IgG antibody,

37 pepsinogen I, and gastrin levels. Lancet 1989;i:6\%-2. gastritis. Am f Gastroenterol 1987;82:245-7.

38 Lee FI, Samloff IM Hardman M Comparison of tripotassium di-citrato bismuthate tablets with ranitidine in healing and relapse of duodenal ulcers. Lancet 1985;i: 1299-302.

39 Baxter A, Campbell CJ, Cox DM, Grinham CJ, Pendlebury JE. Proteolytic activities of human Campylobacter pylori and ferret gastric campylobacter-like organism. Biochem Biophys Res Commun 1989;163:1-7. 